\title{
Ambiente Virtual Tangível para Integração Sensorial no Ensino de Ciências numa Perspectiva Inclusiva
}

\author{
João Carlos Gluz ${ }^{1}$, Liliana Maria Passerino ${ }^{1}$, Evandro Preuss ${ }^{1}$, \\ Ivan Luis Feix Baierle ${ }^{2}$, Mely Paula Rabadan Cimadevila ${ }^{1}$ \\ ${ }^{1}$ Pós-Graduação em Informática na Educação/UFRGS - Porto Alegre - RS - Brasil \\ ${ }^{2}$ Mestrado em Computação Aplicada/UNISINOS - São Leopoldo - RS - Brasil \\ jcgluz@gmail.com, lpasserino@gmail.com, evandro.preuss@gmail.com, \\ ibaierle@hotmail.com, melycimadevila@gmail.com
}

\begin{abstract}
A tangible virtual learning environment integrates virtual reality technologies and tangible interfaces. The educational advantages of using such devices in educational settings are well known, but their integration is an aspect still to be explored especially considering the challenges of inclusive education. In this context, the attention is focused on more complex learning that involves the scientific concepts from mediated activities. This work presents a research that seeks to analyze the construction of an innovative teaching environment capable of integrating tangible technologies and virtual reality applied to science teaching in an inclusive perspective, with students with communication deficits.
\end{abstract}

Resumo. Um ambiente de ensino virtual tangivel integra as tecnologias de realidade virtual e interfaces tangíveis. São conhecidas as vantagens educacionais do uso de tais dispositivos em espaços educativos, mas sua integração é um aspecto ainda a ser explorado especialmente considerando os desafios da educação inclusiva. Neste contexto, o foco de atenção centra-se em aprendizagens mais complexas que envolvem os conceitos cientificos a partir de atividades mediadas. Este trabalho apresenta uma pesquisa que busca analisar a construção de um ambiente de ensino inovador capaz de integrar tecnologias tangiveis e realidade virtual aplicado ao ensino de Ciências numa perspectiva inclusiva, com alunos com déficits na comunicação.

\section{Introdução}

Um ambiente de ensino virtual tangível é um ambiente que integra as tecnologias de realidade virtual e interfaces tangíveis, aliando os benefícios da manipulação de objetos reais para realizar determinada função no ambiente virtual com as funcionalidades dos ambientes virtuais 3D, como a interatividade, a socialização e a facilidade em simular ambientes reais. Esse tipo de ambiente se baseia numa interação natural baseada em artefatos físicos como parte dos componentes da interface de usuário (Ishii, 2008) e proporciona um incremento no engajamento e motivação dos alunos, permitindo a aprendizagem por exploração (Lesley et al. 2008).

Nesse contexto a questão de pesquisa investigada neste trabalho pode ser analisada em dois eixos: um eixo tecnológico voltado a descobrir como pode-se construir um ambiente de ensino inovador capaz de integrar tecnologias tangíveis e realidade virtual aplicado ao ensino de Ciências com o público-alvo; e um eixo educacional que 
VII Congresso Brasileiro de Informática na Educação (CBIE 2018)

Anais do XXIX Simpósio Brasileiro de Informática na Educação (SBIE 2018)

visa acompanhar e analisar processos de formação de conceitos científicos no ensino de Ciências em sujeitos com déficits na comunicação nos anos finais da educação básica. $\mathrm{O}$ presente artigo apresenta os resultados obtidos no eixo tecnológico.

Da temática proposta foi estabelecido como área científica o ensino de Ecologia e como locus de ensino o Parque Estadual de Itapeva, um parque litorâneo situado no município de Torres (RS) e sua escolha é importante no contexto de um ambiente virtual, porque fornece a estrutura dos cenários e personagens ligados narrativamente na construção dos conceitos de ciências a partir de uma proposta de estudo de ecossistemas em risco de extinção. Sobre o recorte no perfil dos participantes, optamos pela deficiência de comunicação como nosso perfil de análise. A deficiência na comunicação é uma condição na qual o sujeito deteriora suas interações sociais em decorrência de déficits primários ou secundários na comunicação. Camargo et al (2008) afirmam que implantar ambientes inclusivos não é algo abstrato ou subjetivo senão que há variáveis específicas como tipo de deficiência e conteúdo ensinado e que o ensino deve ir além de princípios gerais atendendo essas variáveis específicas.

\section{Integração Sensorial: Percepção e Representação para a Construção de Conceitos Científicos}

A Integração Sensorial é uma técnica para problemas de aprendizagem desenvolvida por Jean Ayres (1969). Essa técnica terapêutica foi posteriormente utilizada com pessoas com disfunções neurológicas ou síndromes, como Autismo e pessoas com Alzheimer- Num resgate da proposta original de Ayres (1969) propomos a integração sensorial nos processos e aprendizagem de conceitos científicos em crianças com déficit de comunicação ${ }^{1}$. A integração sensorial é um processo de intervenção que promove sensorialmente a capacidade perceptiva do cérebro obrigando-o a organizar uma resposta adaptativa às diferentes informações recebidas sensorialmente. Essa organização sensorial é essencial para a interação social, para a atenção e o desenvolvimento de outras habilidades motoras (Ayres, 1969). A interpretação correta da informação sensorial permite planejar ações adaptadas ao ambiente, a partir dos diferentes sistemas sensoriais, em particular o sistema tátil, o sistema proprioceptivo e o sistema vestibular ${ }^{2}$ (Bundy et al., 2002).

A percepção é um Processo Psicológico Superior (PPS) que se desenvolve de forma integrada com os demais PPS. Segundo Vygotsky (1991) é um processo dialético, complexo, multidimensional que se caracteriza pela continuidade, sem estágios bruscos, porém com desigualdade no desenvolvimento de diferentes processos psicológicos que passam por transformações qualitativas a partir da interação social na qual a criança, a partir de fatores internos e externos, dispara processos adaptativos. Para Vygotsky (1991) "as crianças resolvem suas tarefas práticas com a ajuda da fala, assim como dos olhos e das mãos” (p.21). Portanto, percepção, fala e ação estão inter-relacionadas no que se considera percepção cognitiva. A linguagem na criança é tão importante quanto a ação

1 Um déficit de comunicação é uma deficiência na capacidade de receber, enviar, processar e compreender conceitos ou sistemas de símbolos verbais, não verbais e gráficos. Tais distúrbios podem ser evidenciados nos processos de audição, linguagem e / ou fala e pode variar de leve a profunda sua gravidade (ASHA, 2018).

2 Em nossa plataforma o sistema tátil e o proprioceptivo são os que têm maior foco na investigação com sujeitos com déficits na comunicação. 
VII Congresso Brasileiro de Informática na Educação (CBIE 2018)

Anais do XXIX Simpósio Brasileiro de Informática na Educação (SBIE 2018)

pois apresenta duas funções a de comunicar e a cognitiva (Vygotsky, 1991). Para Vygotsky (1991) a função psicológica não existe de forma isolada, "a relação entre o uso de instrumentos e a fala afeta várias funções psicológicas, em particular a percepção, as operações sensório-motoras e a atenção, cada uma das quais é parte de um sistema dinâmico de comportamento" (p.24). Portanto, o uso de meios artificiais (atividade mediada) é a forma radical de operar psicologicamente com o mundo.

A criança percebe o mundo, como afirma Vygotsky (1991) não somente pelo olhar, mas também pela linguagem. Elementos independentes num campo visual são percebidos simultaneamente, pois a percepção visual é integral, simultânea. A fala, que é sequencial, separa, isola, rotula elementos numa estrutura sucessiva. Ambos processos são essenciais para planejar a ação e internalização de signos e conceitos. Quando nos deparamos com crianças que apresentam déficits na sua comunicação (especialmente a oral mas não somente) percebe-se as consequências para compreensão perceptiva do mundo e como isso afeta no processo de formação de conceitos.

Para Davydov (1988) toda atividade pedagógica mediada deve ser desenvolvida a partir da interação com objetos e fenômenos que envolvem três níveis diferenciados de generalização: o perceptivo, o representacional e o conceitual. O perceptivo é o nível inicial e fundamental para o processo de formação de conceitos, uma vez que é a partir da capacidade de "observar" objetos e fenômenos que produzimos as representações visuais, auditivas e táteis-motoras levam ao nível representacional.

É por meio de processos de análise-síntese e síntese-análise, que o conceito surge (Davydov, 1988). Sua aquisição se concretiza pelo uso do símbolo em ações de mediação (triádicas) por meio das quais os participantes negociam e constroem o significado de forma intersubjetiva. Serão, pois, tais ações o fio condutor da atividade dando um sentido para a mesma e na que participam ativamente os agentes e suas agências (tecnologias entre outros instrumentos de agenciamento).

Na perspectiva sócio histórica o aprender é uma ação que se estabelece a partir de um processo social. Nessa visão os processos inclusivos tornam-se foco de atenção quando consideramos as aprendizagens mais complexas que envolvem os conceitos científicos. Este aspecto torna-se fundamental se considerarmos nosso público-alvo do ambiente proposto que são crianças com déficit de comunicação.

\section{Estado da Arte}

As Interfaces Interativas Tangíveis (IIT), que usam artefatos físicos como parte dos componentes da interface de usuário (Ishii, 2008), surgem no começo do ano 2000 (Ullmer et al., 2001) mas tornam-se acessíveis a partir de 2005 (Marco et al. 2009; Marshall, 2007). Esses componentes podem ser uma representação física de um objeto digital ou atuar como um controle para a manipulação de um objeto ou informação. Uma mesa tangível é uma IIT que permite interações em sua superfície com objetos físicos reais, identificados na sua base com marcadores fiduciais para reconhecimento das interações e pode ser utilizada em tarefas cognitivas que envolvem representações visuais, sonoras, táteis e simbólicas de objetos.

No uso educacional, autores citam que o uso de interfaces tangíveis apresenta consideráveis vantagens e um incremento no engajamento e motivação dos alunos, assim como aprendizagem por exploração (Lesley et al. 2008) e se revelaram recursos de tecnologia assistiva particularmente adequados para fins educacionais. Para 
VII Congresso Brasileiro de Informática na Educação (CBIE 2018)

Anais do XXIX Simpósio Brasileiro de Informática na Educação (SBIE 2018)

Sitdhisanguan et. al. (2012) o uso de interfaces tangíveis com crianças com déficit na linguagem permite desenvolver a coordenação motora fina, ao mesmo tempo em que se apropriam de metáforas (representações visuais e simbólicas de outros objetos) que é um dos déficits em processos de comunicação. Chen (2012) apresenta uma comparação entre vários trabalhos com mesas tangíveis com enfoque na aprendizagem colaborativa, desenvolvimento de habilidades sociais e de linguagem expressiva em crianças com Transtorno do Espectro Autista (TEA). Outros estudos também mostram que o uso das mesas interativas tangíveis apresenta resultados positivos em atividades educacionais que envolvem crianças (Cerezo, 2015), pessoas com deficiência (Marshall, 2003) e crianças com TEA (Silva, 2015; Zancanaro, 2014; Chen, 2012).

A tecnologia de Realidade Virtual (RV) é um conjunto de tecnologias de interface de sistemas computacionais, que oferece a possibilidade de criar uma sensação de interação realista tridimensional em um espaço físico simulado em tempo real, de tal forma que pessoas interagindo com tais ambientes percebem uma pseudo-realidade bem próxima da realidade em termos visuais (Kumar et al., 2008; Messinger et al., 2009). Atualmente já existem vários exemplos de uso dessa tecnologia na criação dos mais diversos tipos de ambientes e aplicações educacionais como laboratórios virtuais (Amaral et al., 2012), simuladores para o ensino de Física (Greis E Reategui, 2010) ou suporte à acessibilidade (Piovesan et al., 2013; Sgobbi et al., 2014). Um dos principais diferenciais do uso de RV na educação é que as tecnologias de RV permitem não apenas a simulação de mundos reais, em um contexto virtual digital, mas efetivamente permitem concretizar a experiência de pertencimento a uma realidade ficcional ou imaginária.

Estudos indicam que o uso de RV em atividades com autistas registram aumentos significativos nas medidas cognitivas sociais da teoria da mente e do reconhecimento de emoções, bem como no funcionamento social e ocupacional da vida real, sugerindo que a plataforma de realidade virtual é uma ferramenta promissora para melhorar as habilidades sociais, a cognição e o funcionamento do autismo (Kandalaft, 2013). Acredita-se que a RV oferece benefícios específicos para crianças no espectro do autismo, pois ela oferece simulações de situações autênticas do mundo real em um ambiente controlado e seguro e Parsons (2011) e Bellani (2011) apresentam as evidências e trabalhos publicados nos últimos anos envolvendo como o potencial da RV nesse contexto tem sido explorado.

\section{Ambiente de Ensino Virtual Tangível}

O Ambiente de ensino Virtual Tangível (AVT) desenvolvido envolve a integração de uma Mesa Tangível (MT) e um ambiente de Realidade Virtual (RV) 3D para executar e apresentar atividades pedagógicas para a formação de conceitos científicos. A atividade pedagógica envolve a interação com objetos tangíveis na superfície da mesa para realizar experimentações, resolver desafios e jogos e interagir com o mundo virtual. A comunicação entre a MT e o ambiente de RV se dá através de um framework de comunicação especialmente desenvolvido no projeto. A Figura 1 apresenta a integração entre a MT e o ambiente de RV na execução de uma atividade pedagógica. 


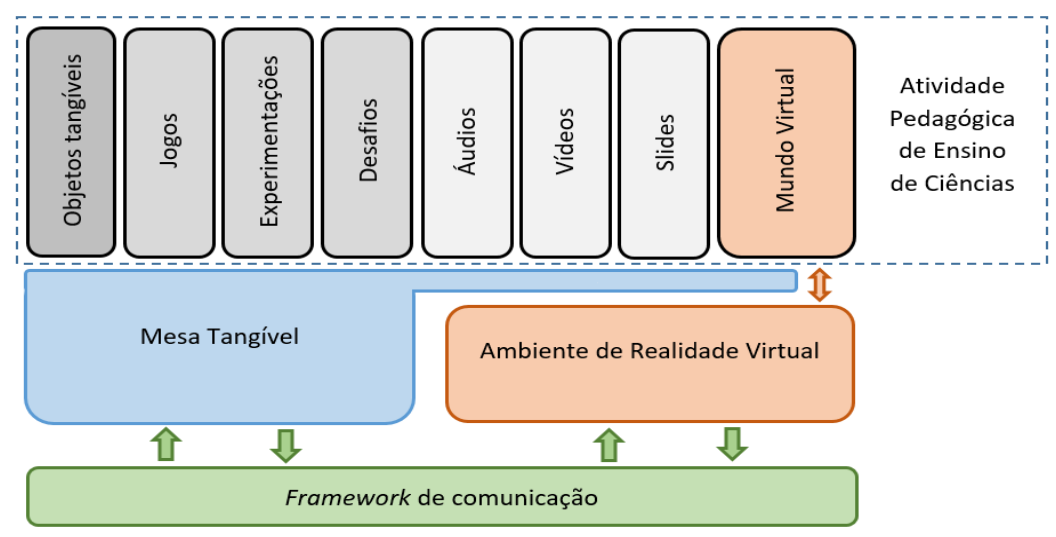

Figura 1. Integração da mesa tangível e realidade virtual numa atividade pedagógica

O contexto de pesquisa centra-se no ensino de Ecologia para séries finais do ensino fundamental numa perspectiva inclusiva, para que alunos com diferentes condições cognitivas/perceptivas possam participar plenamente e interagir com fenômenos e objetos do ambiente. O Parque Estadual de Itapeva, situado na praia de Torres, RS é o cenário escolhido para o AVT. A paisagem é formada por grandes extensões de areias e vegetação esparsa formada por capões e vegetação baixa de gramíneas.

No AVT se desenrola a história educativa, “Aventuras em Itapeva”. As atividades interativas dessa história proporcionam experiências que desenvolvem temática científica associada ao ensino de ciências tendo como personagens duas crianças ou jovens, estudantes. No total foram criadas 16 cenas educativas diferentes com diversas atividades cognitivas visando a formação dos conceitos. Neste artigo apresentamos um exemplo de roteirização desenvolvido.

Na concepção do cenário, história e roteiro, considerou-se a acessibilidade nas imagens, conteúdo e linguagem com vistas a atender alunos com diversidade funcional, na qual a deficiência torna-se uma forma de funcionamento diferenciado, não necessariamente incapacitante. Para o roteiro foram desenvolvidas narrativas visuais visando: a) ampliação das possibilidades de percepção e comunicação de conceitos científicos; b) realização de experimentações e vivências através de desafios propostos, enfatizando a relevância dos assuntos tratados e a construção das representações dos conceitos científicos abordados no ambiente. Os personagens da "Aventura em Itapeva" são a professora Marli, responsável pela introdução dos objetivos do jogo educativo, a guarda florestal Dona Pitaia, que acompanha os alunos em suas aventuras, além dos personagens antropomórficos, o senhor Sapinho-de-barriga-vermelha e a dona Lagartixa-de-praia, que participam de cenas e desafios específicos. O Quadro 1 exemplifica a roteirização pedagógica de uma atividade no ambiente de RV e na MT.

A construção do roteiro se deu de maneira colaborativa numa equipe multidisciplinar com a participação de pesquisadores oriundos das ciências humanas e exatas, com formação e experiência tanto em educação especial como em desenvolvimento de sistemas imersivos e tecnologias tangíveis. O roteiro foi validado com uma professora de sala de recursos. Além disso, os cenários deram base para pensar os processos integrados em ambas plataformas (RV e MT) além dos conceitos de integração sensorial desejados a partir da inserção dos elementos e personagens nos cenários. 
VII Congresso Brasileiro de Informática na Educação (CBIE 2018)

Anais do XXIX Simpósio Brasileiro de Informática na Educação (SBIE 2018)

Quadro 1. Exemplo da roteirização pedagógica de uma atividade na RV e na MT

\begin{tabular}{|c|c|c|c|}
\hline $\begin{array}{l}\text { Cena (I): Sala de aula na } \\
\text { RV }\end{array}$ & \multicolumn{3}{|c|}{$\begin{array}{l}\text { Descrição: Ingresso na RV, início da história na RV, sala de aula do Beto e da } \\
\text { Bia }\end{array}$} \\
\hline Conceito/Ação & Mediação & Recurso/Local & Diálogo/Fala \\
\hline $\begin{array}{l}\text { Localização geográfica } \\
\text { 1- Apresenta a atividade } \\
\text { em Itapeva } \\
\text { 2- Convida a escolher o } \\
\text { avatar para iniciar o jogo } \\
\end{array}$ & $\begin{array}{l}\text { Mediação: por } \\
\text { interação com } \\
\text { texto e voz da } \\
\text { personagem } \\
\text { profa. Marli }\end{array}$ & $\begin{array}{l}\text { 1- Gravação da } \\
\text { apresentação } \\
\text { 2-Interface de } \\
\text { escolha de avatar na } \\
\text { RV }\end{array}$ & $\begin{array}{l}\text { Profa. Marli: "Alunos vamos participar } \\
\text { de uma aventura pedagógica em } \\
\text { Itapeva"! }\end{array}$ \\
\hline $\begin{array}{l}\text { A profa. Marli já está na } \\
\text { SR, entram o avatar } \\
\text { (Beto ou Bia) e seu } \\
\text { acompanhante virtual }\end{array}$ & $\begin{array}{l}\text { Mediação: voz da } \\
\text { profa. Marli }\end{array}$ & $\begin{array}{l}\text { Interface texto da } \\
\text { RV/Voz da profa. } \\
\text { Marli/slides }\end{array}$ & $\begin{array}{l}\text { Profa. Marli: "Alunos, assistam aos } \\
\text { slides" } \\
\text { Slides: serão no formato de imagens. }\end{array}$ \\
\hline $\begin{array}{l}\text { Profa. Marli relembra o } \\
\text { desafio e a mochila com } \\
\text { equipamentos e desafia } \\
\text { os alunos a buscar os } \\
\text { itens necessários na mesa } \\
\text { tangível e colocá-los na } \\
\text { mochila }\end{array}$ & $\begin{array}{l}\text { Mediação: } \\
\text { interação } \\
\text { multimeio ( RV } \\
\text { para MT) }\end{array}$ & $\begin{array}{l}\text { Interface texto na } \\
\text { RV/Voz da profa. } \\
\text { Marli/Mochila na } \\
\text { RV }\end{array}$ & $\begin{array}{l}\text { Profa. Marli: "Atenção alunos, vocês } \\
\text { devem buscar os itens que devem } \\
\text { constar da mochila para que possamos } \\
\text { iniciar nossa ida ao Parque" }\end{array}$ \\
\hline $\begin{array}{l}\text { Cena (I): Desafio } \\
\text { Mochila na MT } \\
\end{array}$ & \multicolumn{3}{|c|}{ Descrição: atividade de mediação formado por um desafio realizado na MT } \\
\hline $\begin{array}{l}\text { Atividade: Na MT a tela } \\
\text { inicial é a mochila e os } \\
\text { objetos tangíveis : } \\
\text { bússola, kit primeiros } \\
\text { socorros, proveta, tablet, } \\
\text { sacos de lixo } \\
\text { Objetivo: identificar os } \\
\text { objetos da mochila. }\end{array}$ & $\begin{array}{l}\text { Mediação: } \\
\text { Interação } \\
\text { multimeio (MT } \\
\text { para RV) }\end{array}$ & $\begin{array}{l}\text { Voz da profa. Marli } \\
\text { objetos tangíveis } \\
\text { na MT }\end{array}$ & $\begin{array}{l}\text { Tela 1 Mochila : Voz 1: "Alunos, } \\
\text { descubram que objetos deverão colocar } \\
\text { na mochila para seguir sua "Aventura } \\
\text { em Itapeva"; Voz 2: "Esse não é um } \\
\text { dos objetos que serão utilizados. siga } \\
\text { buscando"; Voz 3: "OK, você acertou, } \\
\text { coloque o objeto dentro da mochila e } \\
\text { confira na lista" } \\
\text { Tela } 2 \text { Lista: Voz } 4 \text { : "Alunos abram a } \\
\text { lista e verifiquem se já tem todos os } \\
\text { objetos necessários"; Voz 5: "Sim" ... }\end{array}$ \\
\hline
\end{tabular}

O cenário de RV serve de fio condutor da história "Aventuras em Itapeva" e simula uma visita virtual, interativa, animada e autoexplicativa ao parque, que expõe e ensina sobre a preservação do Parque de Itapeva e os problemas que a poluição e o crescimento urbano têm provocado, ao mesmo tempo que permite a manipulação de objetos virtuais dentro do ambiente (Tomedi, 2017). O design da praia e dos ambientes que a envolvem, foram realizados com base em visitas de campo que coletaram fotos e vídeos in loco combinados com fotos via satélite do relevo e das dimensões do local, visando simular o ambiente do parque e da praia o mais próximo possível da realidade.

O mundo virtual criado é dividido em cenas onde o jogo ou história educativa se desenrola. $\mathrm{O}$ envolvimento e a interação dos usuários com a cena são promovidos por um agente pedagógico inteligente na forma de um NPC (Non-Player Character) capaz de interagir em linguagem natural e atuar em diferentes papéis com objetivos educacionais. O mundo virtual conta com placas para orientações e instruções, e objetos. Os agentes pedagógicos têm como objetivo principal, explicar, guiar, interagir e lançar desafios aos usuários, através de interações próximas da linguagem natural, sobre o parque, e os ambientes simulados, como a praia, o charco, as dunas, a importância dos ambientes para cada espécie e demais interações sobre as dúvidas dos alunos. As interações em linguagem natural com cada usuário ocorrem por meio do serviço de mensagens instantâneas do mundo virtual. 
VII Congresso Brasileiro de Informática na Educação (CBIE 2018)

Anais do XXIX Simpósio Brasileiro de Informática na Educação (SBIE 2018)

A mesa tangível foi construída utilizando uma estrutura de madeira com uma superfície de acrílico e vinil translúcido, LEDs de infravermelho, um projetor, uma câmera de infravermelho e um computador. A imagem da aplicação é projetada na superfície do tampo da mesa com o auxílio de um espelho e os objetos com seus elementos fiduciais de marcação em sua base são posicionados sobre a mesa para realizar as interações. A imagem da superfície da mesa, iluminada pelos LEDs de infravermelho, é capturada pela câmera e enviada para oframework reacTIVision (Kaltenbrunner, 2009), que reconhece a identificação e o posicionamento dos fiduciais. O software da MT recebe e interpreta esses dados e exibe a aplicação no projetor. O software construído para a MT compreende um editor, um player e uma biblioteca com os protocolos de comunicação com os demais dispositivos e aplicações. Este software foi desenvolvido com HTML5 e JavaScript e permite que aplicações sejam criadas de forma interativa com o editor, que gera os códigos para sua execução no player (navegador) e exibição na MT. A comunicação com o ambiente de RV é realizada através de web services. A Figura 2 mostra a estrutura da mesa e seus componentes e a imagem da mesa construída.
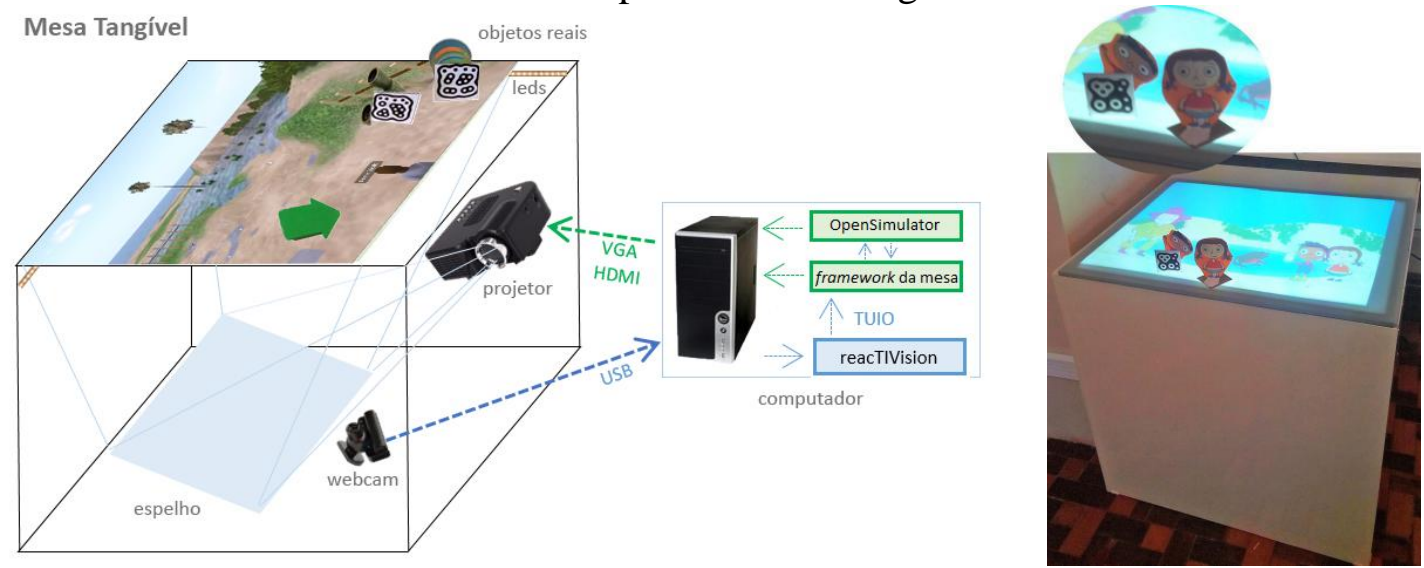

Figura 2. Esquema de componentes de mesa tangível e mesa construída

O player executa e apresenta as histórias ou objetos educacionais criados no editor e faz a interação com o ambiente de realidade virtual. A mesa também serve de interface para a movimentação no ambiente de RV, com o uso dos objetos tangíveis e quando há uma tarefa ou atividade para ser resolvida, a mesa interrompe a execução da RV, exibe e realiza a interação. Desafios, quebra-cabeças, puzzles, etc. são resolvidos na mesa, onde o aluno entra em algum cenário do jogo ou mundo virtual educativo e tem que resolver um desafio que tem aspectos tangíveis que só a mesa pode suportar. Ao final da tarefa ou desafio, a mesa retorna o resultado para o ambiente de RV e continua a sua exibição.

O mundo virtual foi dividido em mundo principal e mundos secundários. O mundo principal é composto das seguintes cenas: (I) inicial, (II) escola, (III) entrada do parque (Figura 3 - lado esquerdo), (IV) charco (Figura 3 - centro), (V) praia, (VI) charco do cágado-preto e (VII) dunas da lagartixa-da-praia. Os mundos secundários, apresentam cenas com desafios específicos que representam recortes das cenas principais, porém em escala muito maior, com o objetivo de permitir ao aluno vivenciar os problemas dos pequenos animais do parque. A primeira destas cenas é o charco onde vive o sapo-debarriga-vermelha (Figura 3 - centro). Cada cena do mundo virtual de Itapeva possui desafios educativos, que devem ser resolvidos ou com a ajuda da MT como no caso da mochila na primeira cena do jogo educativo, ou diretamente no mundo virtual como no desafio de coleta de lixo que ocorre na cena (IV) (Figura 3 - lado direito). Neste desafio 
VII Congresso Brasileiro de Informática na Educação (CBIE 2018)

Anais do XXIX Simpósio Brasileiro de Informática na Educação (SBIE 2018)

o agente pedagógico, na forma do próprio sapinho, conta sua versão dos fatos sobre o impacto ambiental causado pelos seres humanos e do lixo gerado, para que o aluno consiga entender a situação e possa chegar a uma conclusão e avançar em sua missão principal.

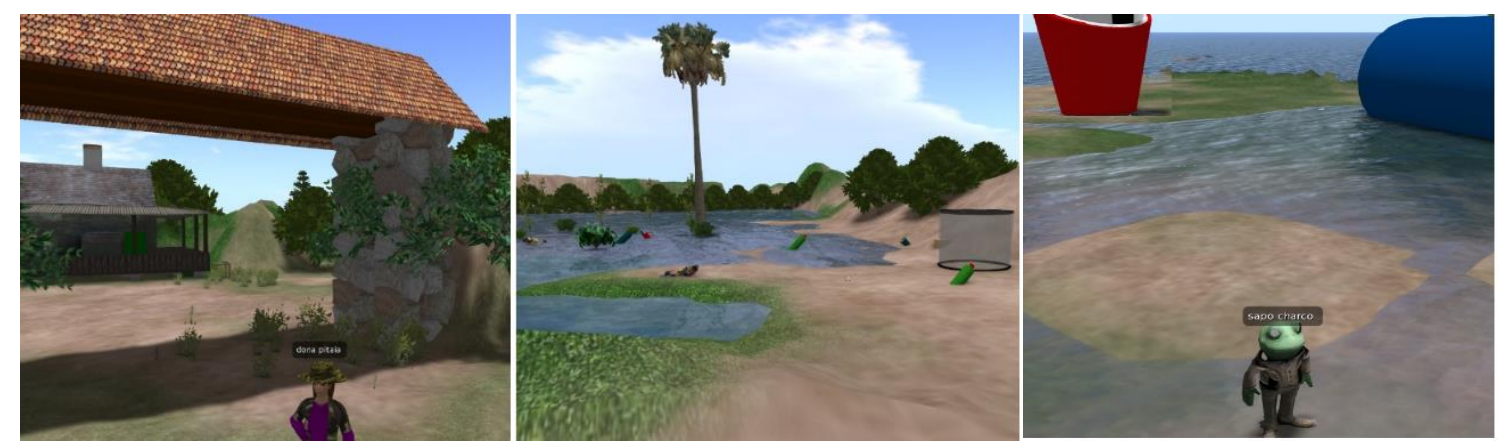

Figura 3. Entrada do parque, charco e cenário em escala maior

Na MT, cada desafio é apresentado exibindo imagens pictográficas e um áudio explicando o contexto e a tarefa. Os objetos reais com os marcadores fiduciais devem ser posicionados em áreas específicas e, para cada movimentação, um feedback com áudio e pictogramas é apresentado. No primeiro desafio da mochila, uma imagem de uma mochila aberta é exibida na mesa e o aluno precisa escolher quais elementos ele colocará na mochila para levar na aventura de Itapeva. Para cada escolha e interação um feedback e novas instruções são apresentadas até que a tarefa esteja concluída. Ao finalizar a tarefa, o resultado da mesma é enviado para o ambiente de realidade virtual, que volta a ser exibido na superfície da mesa, dando sequência à atividade.

\section{Experimentos e Avaliação}

O protótipo do AVT foi desenvolvido durante o final de 2017 e início de 2018 e incluiu o desenvolvimento da MT e do software da MT, a construção de uma aplicação de desafio na MT para uma das cenas da história educativa "Aventuras em Itapeva", o design e a criação do mundo virtual contendo todas as cenas dessa história, o design dos personagens 3D da história e o software dos agentes pedagógicos.

No final do primeiro semestre de 2018 este protótipo foi submetido a uma série de experimentos e testes em laboratório para validar funcionalmente as cenas (I), (II), (III) e (IV) do mundo principal, e a cena (IVb) do mundo secundário, que contém o ambiente do sapinho em escala ampliada. Estes experimentos testaram a operação dos agentes pedagógicos e objetos animados de cada cena, a continuidade e a jogabilidade da história e a integração do ambiente RV com a MT. Os resultados destes testes foram positivos, indicando que o eixo tecnológico do ambiente está de acordo com as necessidades e requisitos especificados e o ambiente está pronto para ser usado em experimentos empíricos em sala de aula no segundo semestre de 2018, para desenvolver o eixo educacional desta pesquisa.

\section{Conclusões}

Os avanços nas pesquisas no que se refere aos ambientes computacionais para apoio e suporte ao ensino, especialmente para crianças com algum tipo de deficiência, envolvem o uso e o aprimoramento de interfaces tangíveis, realidade virtual e ambientes imersivos para fins educacionais. 
VII Congresso Brasileiro de Informática na Educação (CBIE 2018)

Anais do XXIX Simpósio Brasileiro de Informática na Educação (SBIE 2018)

Neste sentido, estes objetos, ambientes e cenários são manipulados e influenciados pelos sujeitos que interagem e participam do processo de construção do conhecimento, através de um manuseio fácil e intuitivo sem conhecimento prévio. Permitir também interação sonora, visual e tátil, necessárias para a integração sensorial no desenvolvimento da percepção. $\mathrm{O}$ ambiente virtual tangível propõe ser um inovador recurso educacional ao permitir desenvolver a coordenação motora fina, a percepção proprioceptiva e tátil, as representações visuais e simbólicas dos objetos e a manipulação cognitiva dos elementos no processo de construção de conceitos científicos.

Este trabalho apresentou uma pesquisa que analisou e apresentou os aspectos tecnológicos e pedagógicos relacionados à construção de um ambiente de ensino inovador capaz de integrar tecnologias tangíveis e realidade virtual aplicado ao ensino de Ciências numa perspectiva inclusiva, com alunos com déficits na comunicação. A integração da mesa tangível com o ambiente de realidade virtual mostrou os desafios de pensar espaços educativos potentes para o ensino inclusivo.

\section{Referências}

Amaral, E., Avila, B.G., Tarouco, L.M. (2012) Aspectos teóricos e práticos da implantação de um laboratório virtual no OpenSim. Anais do SBIE 2012.

ASHA (2018). Definitions of Communication Disorders and Variations. Disponível em <https://www.asha.org/policy/RP1993-00208>

Ayres, A. J. (1969) Deficits in Sensory Integration in Educationally Handicapped Children. Journal of Learning Disabilities, v.2, n.3, pp.160-168, March.

Bellani, M., Fornasari, L., Chittaro, L., Brambilla, P. (2011). Virtual reality in autism: State of the art. Epidemiology and Psychiatric Sciences, v.20,n.3, pp.235-238.

Bundy, A.C, Lane, Sj.J. Murray, E.A. (2002). Sensory integration: theory and practice. Filadelfia: F. A. Davis Company.

Camargo, E.; Nardi, R., Veraszto, E. (2008) A comunicação como barreira à inclusão de alunos com deficiência visual em aulas de óptica. Rev. Bras. Ensino Fís, v.30, n.3.

Cerezo, E., Marco, J., Baldassarri, S. (2015) Hybrid games: designing tangible interfaces for very young children and children with special needs. In More Playful User Interfaces (pp. 17-48). Springer, Singapore.

Chen, W. (2012) Multitouch Tabletop Technology for People with Autism Spectrum Disorder: A Review of the Literature. Procedia Computer Science, v.14, pp.198-207

Davydov, V. V. (1988) La enseñanza escolar y el desarrollo psíquico: investigación teórica y experimental. Tradução: Marta Shuare. Moscú: Progreso.

Greis, L.K., Reategui, E. (2012) Um Simulador Educacional Para Disciplina De Física Em Mundos Virtuais. RENOTE, v. 8, n. 2.

Ishii, H. (2008) The Tangible User Interface and its Evolution. Comms. of ACM.

Kaltenbrunner, M. (2009) reacTIVision and TUIO: a tangible tabletop toolkit. Procs. of ACM Int. Conf. on Interactive Tabletops and Surfaces (ITS '09). NY, USA.

Kandalaft, M. R. et alli (2013) Virtual Reality Social Cognition Training for Young Adults with High-Functioning Autism. Journal of Autism and Developmental 
VII Congresso Brasileiro de Informática na Educação (CBIE 2018)

Anais do XXIX Simpósio Brasileiro de Informática na Educação (SBIE 2018)

Disorders, v. 43, n.1. pp. 34-44.

Kumar, S., Chhugani, J., Changkyu, K., Daehyun, K., Nguyen, et al. (2008) Second Life and the new generation of Virtual Worlds, Computer, v. 41, n. 9.

Lesley, X., Alissa, N., Nima, M. (2008) Are tangible more fun? Comparing children's enjoyment and engagement using physical, graphical and tangible user interface. Procs. of TEI'2008, Bonn, Germany, pp 191-198

Marco, J, Cerezo, E., Baldassarri, S. Mazzonne, E. Read, J. (2009) Bringing Tabletop Technologies to Kindergarten Children. Procs. of 23 rd BCS Conf. on Human computer Interaction. Cambridge University. 1-4 september. p.103-111.

Marshall, P. (2007) Do tangible interfaces enhance learning? Procs. of 1st Int. Conf. on Tangible and Embedded Interaction. Pages NY, USA.

Marshall, P.; Prince, S.; Rogers, Y. (2003) Conceptualizing tangibles to support learning. Procs of Interaction Design and Children (IDC). ACM Press, New York.

Messinger, P. R., Stroulia, E., Lyons, K., Bone, K., Niu, R.H., et al. (2009) Virtual Worlds - past, present and future: New directions in social computing, Decision Support Systems, v. 47, n. 3, June.

Parsons, S., Cobb, S. (2011) State-of-the-art of virtual reality technologies for children on the autism spectrum. Eur. J. of Special Needs Education, v.2, n.3, pp.355-366

Piovesan, S.D., Wagner, R., Medina, R. D., Passerino, L.M. (2013) Sistema Imersivo para Pessoas com Deficiência. Anais do SBIE 2013.

Sgobbi, F. S. et al. (2014) Interação com artefatos e personagens artificiais em mundos virtuais. Anais do SBIE 2014.

Silva, G., Raposo, A., Suplino, M. (2015) Exploring collaboration patterns in a multitouch game to encourage social interaction and collaboration among users with autism spectrum disorder. Computer Supported Cooperative Work, v24, n.2-3.

Sitdhisanguan, K., Chotikakamthorn, N. Dechaboon, A., Patcharaporn O. (2012) Using tangible user interfaces in computer-based training systems for low-functioning autistic children. Pers Ubiquit Comput, v.16, pp.143-155

Tomedi, M. (2017) Evento demonstra importância de conservar biodiversidade no Parque de Itapeva. Portal do Estado do RS (https://estado.rs.gov.br/).

Ullmer, B.; Ishii, H. (2001) Emerging frameworks for tangible user interfaces. IBM Systems Journal, v.39, n. 3-4, pp. 915-931

Vigotski, L. S. (1991) A formação social da mente: o desenvolvimento dos processos psicológicos superiores. Trad. Neto, J. C., Barreto, L.S.M., Afeche, S.C. 4. ed. São Paulo: Martins Fontes, 1991. . A construção do pensamento e da linguagem. Trad. Paulo Bezerra. 2.ed. São Paulo: Editora WMF Martins Fontes.

Zancanaro, M., Giusti, L., Bauminger-Zviely, N., Eden, S., Gal, E. and Weiss P.L. (2014) NoProblem! A Collaborative Interface for Teaching Conversation Skills to Children with High Functioning Autism Spectrum Disorder. In A. Nijholt (Ed.), Playful User Interfaces: Interfaces that Invite Social and Physical Interaction, Singapore. 